CIUDAD Y TERRITORIO

ESTUDIOS TERRITORIALES

ISSN(P): 1133-4762; ISSN(E): 2659-3254

Vol. LII, № 203, primavera 2020

Págs. 33-44

https://doi.org/10.37230/CyTET.2020.203.03

CC BY-NC 4.0

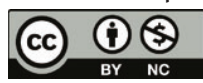

\title{
El informe de impacto de género en el procedimiento de elaboración de los planes de urbanismo
}

César Tolosa-Tribiño

Magistrado del Tribunal Supremo

RESUMEN: La problemática planteada acerca de la exigibilidad del Informe de impacto de género en la elaboración de los planes de urbanismo viene mediatizada por dos cuestiones de carácter general, a las que conviene hacer una breve, pero necesaria referencia. En primer lugar, la cuestión entronca directamente con la naturaleza jurídica de los Planes de urbanismo, esto es, la controversia jurídica nace a partir de la asimilación de los planes de urbanismo con las disposiciones generales. En segundo lugar, y desde una perspectiva más práctica, ha de ponerse de relieve, los graves problemas que la exigencia de cada vez más documentación en la elaboración de los planes, están suponiendo desde la perspectiva de sus posibilidades de impugnación y consiguiente anulación.

PALABRAS CLAVE: Planes de urbanismo. Género. Jurisprudencia. Tribunal Supremo.

\section{The Impact Report about gender on the development of urban master plans}

ABSTRACT: The problem raised about the compulsory inclusion of the Impact Report about Gender in the development of Urban Master Plans is mediated by two general issues, which should be briefly -but necessarily- referenced. The first issue directly connects with the legal nature of Urban Master Plans, which is the legal controversy arisen from the assimilation of Urban Master Plans with general provisions in legal terms. Secondly, and from a more practical perspective, it is necessary to highlight the serious problems coming from the requirement of more and more documentation in the elaboration of planning documents, also in relation to legal impugnation and cancellation.

KEYWORDS: Urban Master Plans. Gender. Jurisprudence. Supreme Court.

Recibido: 04/09/.2019; Revisado: 14.09.2019

Correo electrónico: cesar.tolosa@justicia.es NºRCID: https://orcid.org/0000-0002-9363-3661 


\section{Introducción}

a problemática planteada acerca de la exigibilidad del Informe de impacto de género en la elaboración de los planes de urbanismo viene mediatizada por dos cuestiones de carácter general, a las que conviene hacer una breve, pero necesaria referencia.

En primer lugar, la cuestión entronca directamente con la naturaleza jurídica de los Planes de urbanismo, esto es, la controversia jurídica nace a partir de la asimilación de los planes de urbanismo con las disposiciones generales.

En efecto, mientras que parte de la doctrina y la jurisprudencia, ésta de forma constante y reiterada, han venido considerando a los planes urbanísticos como normas jurídicas de carácter reglamentario, se han seguido manteniendo posiciones que han defendido que el plan urbanístico tiene naturaleza de acto administrativo de carácter general, o una doble naturaleza, en parte normativa y en otra parte no normativa.

Lo cierto es que el Tribunal Supremo ha mantenido sin fisuras la asimilación de los planes a las normas reglamentarias. Así se pone de relieve por la Sentencia de 8 marzo 2012. (Recurso de Casación 2305/2008), cuando afirma que:

"La doctrina especializada y la jurisprudencia constante de esta Sala viene considerando que los instrumentos de ordenación territorial y urbanística ostentan la naturaleza de disposiciones de carácter general porque tras su aprobación se incorporan al ordenamiento jurídico, su vigencia y fuerza vinculante permanece de manera indefinida en el tiempo y se consolidan en cada acto de aplicación. También por su específica configuración legal, que expresamente les atribuye los principios de inderogabilidad singular, publicidad y jerarquía normativa, característicos de las disposiciones reglamentarias".

Esta atribución a los planes de carácter reglamentario, se encuentra en la base de la exigencia de la incorporación del informe de impacto de género en los planes urbanísticos, dado que la mayoría de los textos normativos que se citan para reclamar su incorporación a los mismos, son normas que contienen previsiones de carácter general para el ejercicio de la potestad reglamentaria y no de la potestad de planificación urbanística.

En segundo lugar, y desde una perspectiva más práctica, ha de ponerse de relieve, los graves problemas que la exigencia de cada vez más documentación en la elaboración de los planes, están suponiendo desde la perspectiva de sus posibilidades de impugnación y consiguiente anulación.
Por una parte, el legislador, esencialmente el autonómico, pero también el estatal por la vía de la normativa sectorial y en ocasiones por la necesidad de trasponer normativa europea, ha venido convirtiendo la redacción y elaboración de los planes en una especie de "campo minado", en el que los tropiezos se producen por un doble orden de variables: el tiempo desmesurado en su tramitación, lo que provoca la eventualidad de cambios normativos durante la sustanciación del procedimiento que, no siempre, son advertidos y recogidos por el planificador $y$, la cada día mayor complejidad y variedad de la documentación que debe acompañar a la tramitación de los planes.

Por último, aunque ya lo hemos advertido, no podemos dejar de referirnos a la dispersión normativa, dado que muchos de los informes y documentos que deben incorporarse obligatoriamente a los Planes no se contienen, como sería razonable en aras a la seguridad jurídica, en la legislación urbanística, sino que se recogen en normas de naturaleza sectorial, normas de acompañamiento, etc., lo que hace difícil determinar cuáles de tales documentos deben acompañar al Plan, según la regulación que del procedimiento de su elaboración realizan las Comunidades Autónomas.

Como afirma José Antonio Ramos Medrano, (MedRANo, 2017), creo que con rigor:

"Hay que llamar la atención sobre el hecho de que el legislador va añadiendo nuevas tareas al planeamiento urbanístico que, de forma aislada, suponen un avance importante, pero la suma de todas ellas ha supuesto un colapso de esta figura jurídica. No es sólo la evaluación ambiental estratégica, sino que también se le han impuesto otras muchas funciones, como la necesidad de abordar el estudio del paisaje, la eficiencia energética, la cohesión social, el impacto de género, en Andalucía su incidencia sobre la salud, etc. Y todos estos cambios los va introduciendo el legislador sin que la administración local sea capaz de ir asumiendo todas estas funciones en la elaboración de los distintos planes de urbanismo".

En el mismo sentido, afirma Mercedes Fuertes (FueRTES, 2017) que:

"Los antecedentes de este problema son conocidos por cualquier especialista: otorgar naturaleza reglamentaria a los instrumentos de planeamiento los viste en su totalidad con un traje jurídico, con unas consecuencias y efectos que no se ajustan en todos sus extremos a las precisiones que el crecimiento de la atención del planeamiento está generando, a su variopinta extensión, a su diverso contenido y preciso detalle... La complejidad de la elaboración que ocupa años de análisis y centenares de documentos hace que se estén incrementando las actuaciones administrativas con el fin de facilitar la integración 
de los distintos intereses sociales y económicos, la participación de los vecinos, la consideración de su impacto en favorecer la igualdad de sexos, la atención a los dependientes, la consideración del entorno... trámites que se están convirtiendo en un blanco fácil para que un francotirador aniquile el Plan en su totalidad".

\section{Regulación del denominado informe de impacto de género}

\subsection{El Informe de género en la legislación estatal}

El Informe de impacto de género aparece regulado en la legislación estatal, en la Ley 30/2003, de 13 de octubre, sobre medidas para incorporar la valoración del impacto de género en las disposiciones normativas que elabore el Gobierno, lo que supuso dar una nueva redacción a los artículos 22.2 y 24.1.b) de la Ley 50/1997 del Gobierno.

Posteriormente, en la Ley Orgánica 3/2007, de 22 de marzo, para la igualdad efectiva de mujeres y hombres, su artículo 15 establece que el principio de igualdad de trato y oportunidades entre mujeres y hombres informará, con carácter transversal, la actuación de todos los poderes públicos, obligando a las Administraciones Públicas a integrarlo, de forma activa, en la adopción y ejecución de sus disposiciones normativas, en la definición y presupuestación de políticas públicas en todos los ámbitos y en el desarrollo del conjunto de todas sus actividades.

Por su parte en el Real Decreto 1083/2009, de 3 de julio, por el que se regula la memoria del análisis del impacto normativo, se establece que debe contener como uno de sus apartados el impacto por razón de género.

Tras la modificación de la Ley del Gobierno, introducida a través de la Disposición Final tercera de la Ley 40/2015, de Régimen Jurídico del Sector Público (LRJSP), el artículo 26, bajo el epígrafe "Procedimiento de elaboración de normas con rango de Ley y reglamentos", exige que en la preceptiva Memoria de Análisis de Impacto Normativo se incluya un apartado de impacto por razón de género, en el que se analice y valoren los resultados que se puedan seguir de la aprobación de la norma desde la perspectiva de la eliminación de desigualdades y de su contribución a la consecución de los objetivos de igualdad de oportunidades y de trato entre mujeres y hombres, a partir de los indicadores de situación de partida, de previsión de resultados y de previsión de impacto.

Al margen de esta normativa, que como se ha podido comprobar ostenta carácter general y aplicable al procedimiento de elaboración de los reglamentos en el ámbito estatal, la legislación estatal del suelo también se ha hecho eco de las políticas de igualdad y así se refleja en distintos preceptos del actual Texto Refundido de la Ley de Suelo y Rehabilitación Urbana, aprobado mediante el Real Decreto Legislativo 7/2015 (TRLSRU/2015).

En primer lugar, ya el artículo 3.2 del mencionado TRLSRU/ 2015 establece que, en virtud del principio de desarrollo sostenible, las políticas públicas relativas a la regulación, ordenación, ocupación, transformación y uso del suelo deben propiciar el uso racional de los recursos naturales armonizando los requerimientos de la economía, el empleo, la cohesión social, la igualdad de trato y de oportunidades, la salud y la seguridad de las personas y la protección del medio ambiente.

Por su parte, el artículo 20.1.c) del TRLSRU/2015, bajo el epígrafe de criterios básicos de utilización del suelo, ha establecido que las Administraciones Públicas deberán atender, en la ordenación que hagan de los usos del suelo, a los principios de, entre otros, igualdad de trato y de oportunidades entre mujeres y hombres...

\subsection{El Informe de género en la legislación autonómica}

En cuanto a la regulación de las Comunidades Autónomas, como refiere la profesora CARBALLEIRA RIVERA (2016):

"Del análisis de la normativa autonómica se desprenden tres grandes modelos de aplicación del enfoque de género en las políticas urbanísticas.

$\left.1^{\circ}\right)$ En primer lugar, aquellas comunidades autónomas que no hacen referencia expresa a las políticas urbanísticas o territoriales a la hora de aplicar la transversalidad de género, ni en su normativa urbanística ni en la de igualdad. Muchas de estas comunidades prevén, sin embargo, el informe de impacto por razón de género de los reglamentos que aprueben los gobiernos autonómicos, lo que de manera indirecta va a repercutir sobre la materia, sobre todo a raíz de las recientes sentencias del Tribunal Supremo. $2^{\circ}$ ) En segundo lugar, las comunidades autónomas que prevén otros instrumentos o estrategias que permitan valorar la incidencia de las decisiones urbanísticas sobre el género y la igualdad de condiciones. Y, por último, $3^{\circ}$ ) un tercer grupo en que se prevé un informe o estudio de impacto de género de sus planes, programas y actuaciones de carácter urbanístico y territorial, así como aquellas políticas sectoriales que tengan incidencia directa o indirecta (ordenación del territorio, vivienda, movilidad o medio ambiente)". 
Lo cierto es que la tendencia actual, como luego veremos, es la que determina que la mayoría de las Comunidades Autónomas sigan regulando el informe de impacto de género, no en su legislación del suelo y ordenación territorial, sino con un carácter más genérico en las Leyes de Igualdad, resultando que algunas son más específicas que otras en cuanto al tratamiento concreto que debe darse a los planes urbanísticos, dada la peculiaridad de su naturaleza y de su contenido.

Entre las Comunidades que contienen una previsión específica, aparece la Ley $17 / 2015$, de 21 de julio, de igualdad efectiva de mujeres y hombres de Cataluña que, en su art. 53, sí regula de forma independiente y expresa la "Planificación de las políticas de medio ambiente, urbanismo, vivienda y movilidad", en el siguiente sentido:

"1. Para hacer efectivos los principios a que se refiere el artículo 3, las políticas de medio ambiente, urbanismo, vivienda y movilidad deben:

a) Incorporar la perspectiva de género en todas las fases del diseño, planificación, ejecución y evaluación urbanísticos... [...]"

Para garantizar tales objetivos se establece en el apartado dos de dicho precepto que:

"Las administraciones públicas de Cataluña, para cumplir las medidas a que se refiere el apartado 1, deben garantizar: c) Los estudios de impacto de género y medidas correctoras pertinentes para minimizar los impactos diferenciales en toda actuación urbanística, de vivienda, de movilidad o de medio ambiente".

Muy recientemente se han aprobado dos nuevas Leyes de Igualdad en Cantabria y en Navarra, que vuelven a incidir en una regulación similar en la materia que nos ocupa.

La Ley de Cantabria 2/2019, de 7 de marzo, para la igualdad efectiva entre hombres y mujeres, recoge en su art. 22 la regulación de los "Informes de impacto de género" que deberán incorporarse a los proyectos de ley y a los reglamentos y planes que apruebe el Gobierno de Cantabria.

Sin embargo, la perspectiva de género en las políticas de vivienda, ordenación del territorio, urbanismo y transporte, se recoge en el art. 125 , al afirmar que:

"Las Administraciones públicas de Cantabria integrarán la perspectiva de género en sus políticas y programas en materia de vivienda, ordenación de territorio, urbanismo y transporte, considerando las distintas necesidades de mujeres y hombres".

Cómo puede observarse, al igual que después ocurrirá con la legislación de Navarra, mientras para los proyectos de ley, los reglamentos y planes se exige como requisito formal la existencia de un "Informe de impacto de género", en materia de urbanismo, sólo se obliga a integrar la perspectiva de género en su política urbanística, pero no exige, al menos con la claridad que sería necesaria, un trámite formal y documental concreto.

Esta misma regulación, como se acaba de adelantar, es la acogida por la Ley Foral $7 / 2019$, de 4 de abril, de igualdad entre mujeres y hombres, que regula en su art. 22 "el Informe de impacto de género" y en su artículo 55 las "Políticas de ordenación territorial, urbanismo y medio ambiente", que nuevamente se limita a obligar a integrar la perspectiva de género en su política urbanística, si bien en su apartado 2 , hace referencia a concretos aspectos que deben ser objeto de atención especial, al recoger, que:

"En el diseño de los espacios y planificaciones urbanísticas, se tendrá en cuenta aspectos como la iluminación, longitud de caminos peatonales, distancia desde la parada de autobús o garaje, tipo de accesos, configuración de plazas y jardines y similares, que fomentarán los espacios seguros para una vida libre de violencias contra las mujeres".

Dentro de la legislación urbanística específica, las nuevas normativas autonómicas, pese a la controversia planteada acerca de la exigibilidad del informe de impacto de género, no parecen haber optado por dar soluciones claras que aporten certezas.

A título de ejemplo baste con hacer referencia a una de las nuevas leyes más recientes. En efecto, la Ley 11/2018, de 21 de diciembre, de ordenación territorial y urbanística sostenible de Extremadura, ha venido a establecer una nueva normativa urbanística en dicha Comunidad autónoma.

En la referida Ley, en su artículo 2, dentro de los "Principios generales y fines de la ordenación territorial y urbanística", se incluye:

"La igualdad de oportunidades entre mujeres y hombres, sin que pueda prevalecer desde el plano de la ordenación territorial discriminación de las personas con discapacidad o por razón alguna o circunstancia personal o social, entendiendo que la función pública y el interés general en una sociedad diversa se fundamentan en la atención específica de las necesidades diferenciadas".

Por su parte el art. 10. 5.se refiere de forma específica a la perspectiva de género, señalando que:

"Los instrumentos de ordenación incorporarán en su análisis la perspectiva de género. A estos efectos se incluirá el denominado mapa de riesgos para el urbanismo desde la perspectiva de género con la localización de puntos, zonas o itinerarios considerados como «negros» para las mujeres y una propuesta de medidas para su corrección. 
En concreto, dentro de este apartado se regula el estudio de movilidad que:

"deberá incluir planos de escala y detalle adecuado
con trayectos y conexiones a las principales dotacio-
nes, entre ellas centros docentes y asistenciales. Así
mismo detallará las características del transporte pú-
blico, incluidas entre ellas sus frecuencias y horarios".

Sin embargo, pese a estas declaraciones generales, en el momento de establecer la documentación que debe acompañar a los planes, en relación al Plan General Estructural, la perspectiva o impacto de género sólo forma parte y se integra dentro del estudio de movilidad, que deberá contener según el art. 47 de la Ley un análisis de transporte público, dotaciones, caminos escolares y perspectiva de género, sin que dicha previsión aparezca de forma expresa, por el contrario, en los denominados Planes Generales Detallados.

En definitiva, la perspectiva de género se incorpora, como sucede con la Ley estatal, como un principio general del desarrollo urbanístico sostenible, pero a nivel concreto, sólo se contempla su influencia e incorporación dentro del estudio de movilidad, esto es, se adopta una visión muy limitada del denominado "urbanismo de género".

Hace escasas fechas se ha publicado en el BOE la Ley 1/2019, de 22 de abril, de rehabilitación y de regeneración y renovación urbanas de Galicia, norma que en su art. 3 referido a los "Principios y criterios de la rehabilitación edificatoria y la regeneración y renovación urbanas", señala que:

"1. La Administración de la Comunidad Autónoma de Galicia y las entidades locales de Galicia favorecerán con sus planes, proyectos y programas la rehabilitación edificatoria y la regeneración y renovación urbanas, aplicando los principios de [...] perspectiva de género [...]

2. La planificación de las actuaciones de rehabilitación edificatoria y regeneración y renovación urbanas se ajustarán a los criterios siguientes: [...]

i) La perspectiva de género, teniendo en cuenta los aspectos económicos y sociales".

\subsection{Conclusiones sobre la regulación del Informe de Género}

Visto el contenido de nuestra regulación legal, tanto a nivel estatal como autonómico y en relación con el impacto de género en el ámbito del urbanismo, considero que ha de partirse de una doble perspectiva, que ha de tener una respuesta diferenciada. Desde una primera perspectiva, puramente formal, se trata de dilucidar la exigencia o no de un documento a incorporar a los planes que evalúe su incidencia desde la perspectiva del derecho de igualdad entre hombres y mujeres, de forma tal que su ausencia, pueda dar lugar a un vicio que pueda desembocar, como en otros supuestos de ausencia de documentación en una declaración de nulidad del Plan.

Desde la perspectiva material, lo relevante no es la existencia o no de un determinado documento, esto es de la exigencia de un trámite meramente formal, sino que lo que corresponde es analizar hasta qué punto, la perspectiva de género se ha tomado en consideración e incorporado a la ordenación contenida en el plan.

Lo cierto es que del análisis de la normativa vigente se desprenden muchas dudas acerca de la exigencia o no de los informes de impacto de género, desde la perspectiva formal, en la planificación urbanística. El problema es concretar si la referencia genérica a los Planes que contiene la legislación autonómica al regular su potestad reglamentaria, es posible identificarla con todo tipo de planes, entre ellos los urbanísticos y si dentro de ellos debe resultar de aplicación tanto a la planificación general como a los planes derivados o de desarrollo.

Estas dudas, como es lógico se han trasladado al ámbito judicial, por lo que conviene hacer referencia a las sentencias que se han ocupado de dicha cuestión.

\section{Análisis de jurisprudencia: estudios de caso}

\subsection{La sentencia del plan territorial de la Costa del Sol}

La Sentencia del Tribunal Supremo de 6 de octubre de 2015 (Recurso de casación 2676/2012), aborda por primera vez, la cuestión referida a la exigibilidad en el procedimiento de elaboración del planeamiento urbanístico del informe de impacto de género.

Al analizar la referida sentencia, es importante reparar en que la Sala procedió en primer término a fijar con precisión el derecho aplicable.

Así, se parte del dato de que, en el momento de aprobarse el Plan territorial en cuestión por Decreto de la Junta de Andalucía 142/2006, de 18 de julio, por el que se aprueba el Plan de Ordenación del Territorio de la Costa del Sol Occidental de la provincia de Málaga y se crea su Comisión de Seguimiento, estaba en vigor y era de aplicación, la Ley Andaluza 18/2003, de 29 de diciembre, por 
la que se aprueban medidas fiscales y administrativas, en cuyo artículo 139.1 se disponía que en la tramitación de todos los proyectos de ley y reglamentos que apruebe el Consejo de Gobierno se deberán tener en cuenta de forma efectiva el objetivo de la igualdad por razón de género debiendo, a tal fin, en la tramitación de las citadas disposiciones, emitirse un informe de evaluación del impacto por razón de género del contenido de las mismas. Dicha Ley estaba entonces desarrollada por Decreto 93/2004, de 9 de marzo, por el que se regula el informe de evaluación de impacto de género en los proyectos de ley y reglamentos que apruebe el Consejo de Gobierno, cuyos artículos 2, 3 y 4 establecían su ámbito de actuación, el órgano competente para la emisión del referido informe, así como su contenido.

Por otra parte, la Ley estatal 30/2003, de 13 de octubre, sobre medidas para incorporar la valoración del impacto de género en las disposiciones normativas que elabore el Gobierno, era de aplicación supletoria o analógicamente en virtud de la Disposición transitoria segunda de la Ley 6/1983, de 21 de julio, del Gobierno y Administración de la Comunidad Autónoma de Andalucía.

De esta forma, la sentencia, concluía que, tanto por aplicación del derecho propio autonómico, como por la remisión que, a título de supletoriedad, se hace a la legislación del Estado, en el procedimiento de la elaboración del Plan Territorial debería haberse emitido un informe de evaluación de impacto por razón de género.

A partir de la constatación de la exigencia del citado informe, termina la Sentencia apuntando que, como prevé el propio Decreto 17/2012 regulador del informe de evaluación de impacto de género en su artículo 5.2, para el caso de que la disposición no produzca efectos, ni positivos ni negativos, sobre la igualdad de oportunidades entre hombres y mujeres, reflejará esta circunstancia en el informe de impacto de género, esto es, si se constata la inexistencia de efectos, la administración no queda eximida de elaborar el informe, con independencia de que en el mismo, pueda declararse su neutralidad en materia de igualdad, esto es, debe cumplirse el trámite formal aunque no exista incidencia desde la perspectiva material o sustantiva.

Como puede observarse esta sentencia realiza una interpretación extensiva del concepto de planificación o ejercicio de la acción reglamentaria, dado que en la legislación urbanística andaluza, ninguna previsión se contiene en tal sentido, siendo relevante destacar, en orden a comprender mejor la decisión adoptada por el Tribunal Supremo, que, en sede jurisdiccional, la Junta no negó la exigibilidad del informe, sino sólo su carácter innecesario en el caso enjuiciado, dada la irrelevancia de su contenido desde una perspectiva de género y que junto a tal vicio, el Plan ya había resultado anulado por defectos sustanciales en el trámite de información pública.

Justo es reconocer que, en esta sentencia se contiene un ponderado y muy razonado voto particular de los Magistrados SUAY RINCón y DEL Oro Pulido ${ }^{1}$, que, sin embargo, en ocasiones se ha tomado como una postura divergente con la postura tradicional de la naturaleza reglamentaria de los planes de urbanismo, cuando, creo que e mismo dista mucho de apuntar a esa conclusión. En efecto, el voto afirma con absoluta rotundidad que "los planes urbanísticos y territoriales son disposiciones de carácter general", si bien y esto es lo verdaderamente importante añadía que:

"resulta igualmente difícil de negar la peculiaridad -última, también- que es propia de los planes urbanísticos y territoriales, por cuanto disponen estos instrumentos de ordenación de una regulación específica y completa en el correspondiente sector del ordenamiento jurídico en que se integran".

De tal afirmación, extraen ambos Magistrados, dos conclusiones, sumamente válidas al analizar la cuestión del informe de impacto de género en la planificación urbanística:

" $1^{\circ}$ ) En todo caso, que se convenga en la consideración de los planes urbanísticos y territoriales como disposiciones de carácter general no quiere decir que les resulten de aplicación sin más las mismas previsiones normativas sin excepción de ningún género.

$\left.2^{\circ}\right)$ Por tratarse de disposiciones de carácter general, en suma, no tiene por qué producirse en el caso de los planes una recepción absoluta de las normas reguladoras de los reglamentos estatales y autonómicos. Al menos, en lo que concierne a los aspectos procedimentales ...".

En conclusión, se afirmaba que:

"este informe, atendiendo a la normativa andaluza de aplicación, no se proyecta sobre la totalidad de los instrumentos puestos a disposición de la Comunidad Autónoma para el desarrollo de su acción de gobierno, sino que dicho informe de impacto de

\footnotetext{
1 Del Oro Pulido, M \& Suay Rincón, J.J. (Voto particular, Sentencia de 6 de octubre de 2015. Recurso de casación 2676/2012. Tribunal Supremo)
} 
género contrae su ámbito de aplicación, señaladamente, a los proyectos de leyes y reglamentos cuya aprobación corresponde al Consejo de Gobierno de la Junta de Andalucía."

En definitiva, para el voto particular, la exigibilidad del informe de impacto por razones de género, sólo puede venir previsto por la correspondiente normativa urbanística, si bien aclara que:

"No constituye un óbice absolutamente infranqueable el hecho de que el recurrente deba aportar algún dato (Sentencia de 7 de enero de 2015 R 487/2013), o razón concreta (Sentencia de 6 de mayo de 2009 RC 1883/2007), de los que pueda infundirse la sospecha, al menos con carácter indiciario, de que una norma aparentemente inocua pueda producir determinado impacto de género, según también tenemos declarado",

esto es, para ambos Magistrados, sí resultaba posible un control material del contenido del Plan.

De seguirse tal tesis, habría de concluirse, por tanto, que sólo se exigirá en el procedimiento de elaboración de los planes, la incorporación de la documentación prevista expresamente en la legislación urbanística o en la normativa sectorial que expresamente lo exija (buena prueba de ello, es el pronunciamiento contenido en la sentencia de 5 de febrero de 2019 sobre la nulidad del Plan general de Laredo por falta del preceptivo informe regulado en el artículo 35.2 de la Ley 9/2014, de 9 de mayo, General de Telecomunicaciones), pero no en supuestos que incorporen previsiones genéricas y abstractas.

\subsection{La sentencia del Reglamento de Costas}

El Tribunal Supremo volvió a pronunciarse sobre esta cuestión en Sentencia de 27 de octubre de 2016, $N^{\circ}$ de Recurso: 929/2014, donde en su Fundamento de Derecho Tercero, $2^{\circ}$, estudia el efecto de la falta de análisis de impacto de género en el Reglamento General de Costas, norma reglamentaria que pese a tener notoria influencia en el ámbito urbanístico, no es propiamente una norma de tal naturaleza.

La sentencia, tras la cita del marco normativo estatal de aplicación y la exigencia del informe sobre el impacto por razón de género, constata como el referido informe se limita a señalar que "[e]l impacto en función del género del proyecto es nulo ...", alegando los recurrentes que:

"con ello se infringe de forma grosera la Guía Metodológica redactada por el Ministerio de Presidencia, al confundir la conclusión del análisis con el análisis de impacto de género" y que "el RGC no es una norma ajena o neutra desde el punto de vista del principio de igualdad, que, además, tiene una incidencia territorial significativa al proyectar sus efectos sobre un segmento muy elevado de la población española, y que, en fin, pretende contribuir a la reactivación económica de las zonas litorales."

\section{Según la sentencia:}

"El impacto de género se considera cuando, no existiendo desigualdades de partida en relación a la igualdad de oportunidades y de trato entre mujeres y hombres, no se prevea modificación alguna de esta situación. Y esto es lo acontecido en el supuesto de autos, en el que la recurrente no acierta a determinar cuáles serían las incidencias del nuevo $R G C$ en el régimen de la igualdad entre hombres y mujeres, por cuanto, como hemos expresado, la incidencia del RGC sobre la población o las zonas litorales resultan genéricas y poco cercanas a la afectación de las políticas de género [...] Esto es, la recurrente no ha puesto de manifiesto la existencia de argumento alguno para desmontar el juicio contenido en la MAIN del RGC en el sentido de que la incidencia del mismo en las políticas de género no sea 'nulo'".

En definitiva, según la tesis de la sentencia, habiéndose cumplido, aún de forma más que sintética, con la obligación formal, correspondía a la parte recurrente poner de manifiesto cuáles eran los aspectos con incidencia en la cuestión del género que el Reglamento no respetaba, impugnando de forma concreta, específica y determinada, la declaración administrativa de la inexistencia de tal impacto.

\subsection{La sentencia del Plan de Boadilla del Monte}

Probablemente, la cuestión alcanzó toda su actualidad con la Sentencia del TSJ de Madrid que anuló el Plan General de Boadilla del Monte, un Plan que había sufrido numerosos avatares jurídicos en su tramitación y aprobación.

La tesis central de la sentencia se basa en la existencia de una laguna jurídica, que ha de integrarse con la aplicación supletoria del Derecho estatal que regula la elaboración de las disposiciones reglamentarias del Gobierno.

Como ha señalado Francisco Velasco (Velasco, 2018) el argumento se hace en cuatro pasos:

“a) Razona la Sala, en primer lugar, que el plan general es una disposición de rango reglamentario que aprueba definitivamente el Consejo de Gobierno de la Comunidad de Madrid. En consecuencia, a la aprobación definitiva del Plan General de Madrid 
le sería aplicable la ley que rige el ejercicio de la potestad reglamentaria del Gobierno madrileño: la Ley madrileña 1/1983, de 13 de diciembre, del Gobierno y la Administración.

b) Pero visto que la Ley madrileña 1/1983 no exige un informe de impacto de género enla elaboración de los reglamentos autonómicos, la Sala de lo Contencioso-administrativo considera que estamos ante una laguna jurídica.

c) Por ello, la Sala procede, por mandato del art. 149.3 CE, a aplicar supletoriamente el Derecho estatal, en concreto el art. 26.3 f) de la Ley 50/2007, de 27 de noviembre.

d) En consecuencia: dado que en la elaboración de los reglamentos del Gobierno de España se tiene que incluir un informe de impacto de género, dado que esa regulación es aplicable supletoriamente a los reglamentos de la Comunidad de Madrid, y dado también que los planes son normas reglamentarias que aprueba definitivamente el Gobierno madrileño se llega a la conclusión de que un proyecto de planeamiento urbanístico en la Comunidad de Madrid debe incluir un informe de impacto de género".

Para el citado autor, dos son las debilidades de este razonamiento. Lo primero: el hecho de que la aprobación definitiva de un plan general corresponda a la Comunidad de Madrid no convierte al plan general en un reglamento autonómico. En segundo lugar, recordando a Larenz, sostiene que la identificación de falsas lagunas jurídicas es una de las técnicas más notorias para la expansión del poder judicial, a costa del principio de legalidad, como ha ocurrido en este caso.

Por su parte, como señala Ruiz Arnaiz (Ruız ARNAIZ, 2017), comentando igualmente la citada sentencia:

"Pero lo más llamativo de la Sentencia que ahora comentamos es la justificación que contiene para la exigibilidad del informe de impacto de género, para lo que no duda en afirmar, sin que haya desarrollado medida probatoria o pericial alguna en este sentido que los instrumentos de ordenación pueden causar impacto de género "al regular cuestiones tales como la ubicación y características de los viales y conexión de redes generales y locales en conexión con centros docentes, equipamientos necesarios, transportes y movilidad, una u otra tipología edificatoria (en directa relación con la seguridad pública y para la prevención de agresiones característicamente dirigidas contra la mujer o la ubicación, proximidad y accesibilidad de zonas verdes y parques públicos considerando que [...] es la población femenina la que sigue mayoritariamente asumiendo el cuidado y atención de menores, ancianos y personas discapacitadas, la que conduce para llevar a los hijos al colegio, la que accede mayoritariamente a los centros comerciales y/o grandes superficies para garantizar el suministro y atención de las necesidades básicas de la familia, o, incluso, la que acude prácticamente a diario con menores (propios o entregados a su cuidado, como una de las tareas que, contractualmente, desempeña al servicio del hogar familiar) a parques infantiles cuya proximidad y accesibilidad se revela necesaria para poder conciliar el resto de los quehaceres domésticos, que, también mayoritariamente, sigue todavía teniendo la mujer que atender en solitario. Este tipo de afirmaciones que parece que no cuentan con respaldo experto, pues no indican las fuentes de las que han sido extraídas y de las que no se sabe si son fruto de la impresión general que la Sala tiene formada en relación con el rol que las mujeres desempeñan en nuestra sociedad, no debieran figurar en las resoluciones judiciales. Tampoco se aclaran las razones por las que los instrumentos de ordenación pueden causar impacto por razón de género en los aspectos señalados tales como las características o ubicación de los viales o las tipologías edificatorias: no se alcanza a comprender en qué medida pueden causar un impacto negativo de género o, por el contrario, cómo deben enfocarse tales materias y cuál es el tratamiento que deba dárseles para que el impacto sea positivo".

Más contundente en lo referente a estas sentencias, ha sido la opinión de Tomás Ramón Fernández, (2017) cuando afirma:

\begin{abstract}
"Los términos en que se planteó el problema no pueden ser más llamativos: el recurrente simplemente denunció la falta del informe de impacto de genero sin molestarse lo más mínimo en indicar siquiera la importancia que tal omisión pudiera tener para la defensa y protección de sus legítimos derechos, lo que demuestra que no le afectaba ni poco, ni mucho, ni nada y la Sala se limitó a constatar que la colección de tramites no estaba completa y sin importarle tampoco la incidencia que el tramite omitido pudiera haber tenido en la legalidad, acierto y oportunidad. del plan impugnado se apresuró a decretar la nulidad radical de este.
\end{abstract}

¿Tiene esto algún sentido? ¡Es razonable declarar nulo de pleno derecho en su totalidad un Plan de Ordenación Territorial al cabo de nueve años! porque se echa en falta un informe que nadie considera que pueda tener transcendencia alguna por su falta absoluta de relación con el objeto del mismo?

Una sentencia reciente del Tribunal Superior de Justicia de Madrid de 19 de abril de 2017 considera que si lo es porque ha anulado por el mismo motivo el Plan General de Ordenación de Boadilla del Monte apoyándose en una larga y circunstanciosa argumentación.

A mí me parece que no lo tiene en absoluto y que, sin necesidad de pedir ayuda al legislador para que cambie las normas aplicables, nuestro más 
Alto Tribunal podía haber resuelto el problema de otra manera dando sencillamente a las formas el valor que realmente tienen, que la ley las otorga y que su propia jurisprudencia las ha reconocido también muchas veces."

Por fin y en referencia a las opiniones en contra, se pregunta Mercedes Fuertes (FuerTES, 2017):

“¿No parece desproporcionado que la inexistencia de tal informe eche por tierra años de trabajo? Luchar por la igualdad, lo mismo que atender a las personas más vulnerables y dependientes, o preocuparse y cuidar del entorno son presupuestos que debe atender todo Ayuntamiento. Pero me parece algo exagerado que, sin acreditar qué menoscabos concretos para las mujeres, qué perjuicios reales existen para el desenvolvimiento de sus actividades se declare la nulidad de todo un Plan general de ordenación urbana. Porque ¿se ha advertido cómo se están banalizando algunos informes de impacto que quedan reducidos a un cuestionario de preguntas simples sin ninguna argumentación sensata?"

En cualquier caso, la citada sentencia fue recurrida en casación y por Auto de la Sala de Admisión de 17 de noviembre de 2017, se acordó declarar que la cuestión que presentaba interés casacional objetivo:

"consistiría en determinar en qué medida la cláusula de aplicación supletoria del derecho estatal permite sostener la exigencia a las Comunidades Autónomas de un requisito, como es el informe de impacto de género, en materia de ordenación urbanística, que no figura previsto en su propia legislación".

\subsection{Sentencia del Tribunal Supremo, de 10 de diciembre de 2018 , sobre el problema de la supletoriedad del Derecho estatal procedimientos y elaboración de reglamentos por las Comunidades Autónomas}

Sobre el juego de la supletoriedad en los supuestos de procedimientos y elaboración de reglamentos por las Comunidades Autónomas, ya existía un pronunciamiento de la Sala Tercera del Tribunal Supremo en las Sentencias de 7 de febrero de 2012, (recurso 611/2010), y de 29 de mayo de 2012, (recurso 24570/2010), habiendo establecido que de conformidad con la legislación Valenciana, la misma contiene, en el art. 43 del Estatuto de Autonomía, una completa regulación del procedimiento de elaboración de las disposiciones generales que proceden del Consejo de la Generalidad Valenciana y que no necesita ser completado por ninguna norma del Estado en virtud del principio de supletoriedad a que se refiere el artículo 149.3 de la Constitución Española.
Tras recordar la exigencia de un informe sobre el impacto por razón de género en la legislación estatal, la sentencia razona que, la misma,

"constriñe su ámbito de aplicación a la potestad reglamentaria del Gobierno de la Nación, de modo que el mismo no puede reputarse como procedimiento administrativo común a efectos del artículo 149.1.18 de la CE que respeta las especialidades derivadas de la organización propia de las Comunidades Autónomas, y precisamente por ello, tampoco, puede constituir derecho supletorio de acuerdo con lo dispuesto por el artículo 149.3 de la Constitución, porque como ya expusimos la Ley 5/1983, del Consejo de la Comunidad Autónoma Valenciana en el artículo 43 contiene una regulación completa del procedimiento de elaboración de las disposiciones reglamentarias que hace innecesaria por superflua esa supletoriedad del derecho estatal, sin que contradiga esta afirmación la invocación de la disposición final segunda de la Ley $5 / 1.983$ que se refiere precisamente al supuesto de la existencia de una laguna en la regulación autonómica, único supuesto en que sería posible de acuerdo con la doctrina del Tribunal Constitucional sentencias 118/1.996, y 61/1.997, la aplicación supletoria del derecho del Estado".

En conclusión, la cláusula de supletoriedad que se invoca para aplicar el artículo 24 de la Ley de Gobierno en relación con la elaboración del Plan de Ordenación, y por lo tanto exigir el informe de impacto de género como elemento esencial para la aprobación de dicho instrumento urbanístico, no tiene soporte en la actual jurisprudencia que analiza el señalado principio.

Como sobre esta cuestión razona Velasco Caballero (VelAsco, 2018):

"En esta sentencia queda por entero claro que allí donde la legislación urbanística no ha exigido expresamente un previo informe de impacto de género, éste no es exigible, no siendo identificable tal obligación a partir de la aplicación supletoria la regulación de la Ley del Gobierno.

A partir de este caso se puede plantear, ya más en abstracto, cuándo existe verdaderamente un déficit de regulación procedimental o laguna que deba ser integrada con la aplicación supletoria de otra ley (normalmente ley estatal ex art. 149.3 de la Constitución). La cuestión no es sencilla. Es conocida y frecuente, en la práctica jurídica, la identificación ficticia o forzada de una laguna normativa para, precisamente, poder aplicar una norma supletoria. En Derecho administrativo esto se traduce, con cierta frecuencia, en la exigencia de trámites procedimentales no previstos en la ley autonómica que directamente regula una materia, aunque sí en una ley simétrica o próxima del Estado (dictada para su propia Administración). 
Antes los evidentes riesgos de exceso en la aplicación supletoria del Derecho estatal, conviene trazar alguna línea razonable sobre cuándo estamos ante un defecto de regulación y cuándo ante la legítima opción normativa de no regular o no exigir un determinado trámite procedimental. La distinción puede ser esta: La imposición de un concreto trámite o carga procedimental debe ser siempre expresa, en la ley general o sectorial que regula el correspondiente procedimiento administrativo. Esto es, sobre la existencia de un concreto trámite no hay posible laguna normativa: o el trámite en cuestión está previsto expresamente en la ley, o hay que considerar que la opción legal es no incluir tal trámite en la regulación procedimental. Distinto es el caso de cuando la ley (general o sectorial) incluye un trámite concreto, pero no lo regula con detalle. En tal caso sí se puede considerar que, habiendo una opción legal expresa en relación con ese trámite, éste no ha sido regulado con detalle. Habría entonces una laguna normativa, que sí sería integrable por la aplicación supletoria del Derecho estatal ex art. 149.3 CE".

\subsection{La aplicación de la supletoriedad del derecho estatal a la legislación de la Comunidad de Madrid}

La tesis central de la sentencia del TSJ de Madrid, era sostener que debía haberse observado lo dispuesto en el entonces vigente art. 24 de la Ley 50/1997, modificado por la Ley 30/2003, pues, en ausencia de normativa específica autonómica, el art. 33 del Estatuto de Autonomía de la Comunidad de Madrid prevé el carácter, en todo caso, supletorio del Derecho del Estado respecto del propio de la Comunidad Autónoma, esto es, tras reconocer la inexistencia de normativa autonómica que imponga tal requisito, acude a la aplicación de la cláusula de supletoriedad del derecho estatal.

Frente a tal tesis, la Sentencia de la Sala Tercera del Tribunal Supremo, recuerda como, de modo general, la supletoriedad fue entendida, en un inicio, como la principal expresión de una supuesta potestad normativa general del Estado, que venía reconocida ya sea, intrínsecamente en el modelo de Estado constitucionalmente diseñado, en el art. 66.2 CE o en el propio artículo 149.3 CE. De ese modo, se consideró a la supletoriedad, como un título atributivo universal de competencias a favor del Estado, como principal instrumento de garantía de unidad del ordenamiento jurídico y como parámetro de definición de la naturaleza del Estado autonómico.

En ese sentido, el Tribunal Constitucional entendió la supletoriedad del Derecho estatal de manera absoluta ("en todos los casos"), partiendo de la concepción de que el Estado gozaba de una potestad normativa de carácter general que le permitía dictar normativa sobre cualquier materia, sin límites por razón de la misma. De esta manera, el Estado podría dictar las normas jurídicas que desease sobre cualquier ámbito jurídico, en virtud de su potestad normativa general que, según este criterio, venía reconocida en el art. 66.2 CE.

Sin embargo, en la STC $118 / 96$, se vino ya a sostener, modificando la postura inicial, que:

"La supletoriedad no es un vehículo para conferir mayor ámbito de aplicación a la ley del Estado, como refleja la L.O.T.T., sino exclusivamente para cubrir las deficiencias, lagunas o carencias de regulación del Derecho de las Comunidades Autónomas y siempre que su naturaleza propia lo hiciera factible, como puntualizó la STC 179/1985. En otro orden de cosas, el Derecho del Estado que puede resultar supletorio para las Comunidades Autónomas es únicamente el que éste adopte para sí, o sea, en el legítimo ejercicio de sus competencias; de suerte que ni cabe sostener la existencia de una potestad estatal de regulación general de cualquier materia o asunto, al margen del principio de competencia, ni sería lícita, constitucionalmente hablando, la creación del Derecho con la exclusiva finalidad de que fuera supletorio del de las Comunidades Autónomas".

Por su parte las SSTC 15/89; 64/89; 103/89 y 79/92, afirmaron que tal principio de ningún modo permite transformar la supletoriedad en una cláusula universal de atribución competencial, de forma tal que el principio de competencia se convierte en la regla dominante que articula las relaciones entre Estado y Comunidades Autónomas y a la luz de la cual se deben explicar otros principios constitucionales como la supletoriedad.

De esta forma sostiene la STC 118/96 que:

"La cláusula de supletoriedad es... una previsión constitucional emanada de la Constitución que se dirige al aplicador del Derecho, indicándole el modo en que deben colmarse las lagunas del ordenamiento autonómico, cuando las haya.... Una vez que el aplicador del Derecho, utilizando los medios usuales de interpretación haya identificado una laguna en el ordenamiento autonómico, deberá colmarla acudiendo a las normas, pertinentes, dictadas por el Estado en el ejercicio de las competencias que la Constitución le atribuye: en eso consiste la supletoriedad del Derecho estatal que, por su misma naturaleza, no comporta atribución competencial alguna",

añadiendo que:

"La cláusula de supletoriedad no permite que el Derecho estatal colme, sin más, la falta de regulación autonómica en una materia. El presupuesto de aplicación de la supletoriedad que la Constitución establece no es la ausencia de regulación, sino la 
presencia de una laguna detectada como tal por el aplicador del Derecho. Y si ello es así, tal y como dijimos en la STC 147/91, la aplicación supletoria de las normas estatales no puede venir impuesta por el legislador. Pues, de lo contrario, la ley estatal sería aplicable en el ámbito reservado al Derecho autonómico sobre la base de la mera ausencia de regulación autonómica correspondiente y no se limitaría, por lo tanto, a integrar lagunas apreciadas por el aplicador del Derecho, subvirtiéndose el sentido de la cláusula de supletoriedad del Art. 149.3 y arrogándose inconstitucionalmente el Estado la facultad de integrar por sí los distintos ordenamientos de las Comunidades Autónomas, por la vía de dictar normas aplicables supletoriamente".

En consecuencia, para el TC precisar cuándo debe aplicarse el Derecho estatal supletoriamente no corresponde al legislador, sino al operador jurídico cuando detecta la inexistencia de norma autonómica.

En el ámbito urbanístico, la Sentencia del Tribunal Consitucional $61 / 1997$ precisó con claridad que :

"Dado que a partir de los artículos 148 y 149 CE, todos los Estatutos de Autonomía atribuyen a las Comunidades Autónomas, la competencia exclusiva sobre la materia urbanismo, es evidente que el Estado no puede dictar normas supletorias al carecer de título competencia! específico que así lo legitime, sin que, por otra parte, el hecho de ostentar otros títulos competenciales susceptibles de incidir sobre la materia pueda justificar la invocación de la cláusula de supletoriedad del artículo 149. 3 in fine CE".

\subsection{La exigencia del informe de impacto de género en la Comunidad de Madrid}

Partiendo de la anterior doctrina, según el Tribunal Supremo, en el caso del Plan de Boadilla del Monte, desde una perspectiva puramente formal y procedimental, no resultaba exigible la incorporación de un específico informe de impacto de género.

\section{La incidencia del principio de igualdad de género en el urbanismo}

Una vez rechazada la exigencia formal el informe de impacto de género, verdadera cuestión nuclear del litigio y de la decisión en la instancia de declaración de nulidad del Plan, el Tribunal Supremo realiza una afirmación sumamente relevante, que se realiza al inicio de la sentencia, cuando delimitando el objeto de la controversia, se dice que:

"no se trata en este recurso de resolver acerca de la conveniencia u oportunidad de que los instrumentos de planeamiento urbanístico incorporen o no un informe o perspectiva de género, sino de dilucidar si, en este caso, concreto, era necesario..."

Igualmente, conviene destacar la afirmación que realiza la sentencia cuando afirma que:

"ello no es óbice para concluir que por las razones que a continuación expresaremos el principio de igualdad de género no resulta una cuestión neutral en materia de urbanismo".

Alude la sentencia que estamos comentando a que, como antes hemos referido, la propia Ley Orgánica 3/2007 reconoce la transversalidad del principio de igualdad de trato entre mujeres y hombres y como el art. 2. 2 de la Ley del Suelo de 2007 y las Leyes posteriores (art. 3.2, Real Decreto Legislativo 7/2015) han recogido dentro de los principios de desarrollo territorial y urbano sostenible que:

"En virtud del principio de desarrollo sostenible, las políticas a que se refiere el apartado anterior deben propiciar el uso racional de los recursos naturales armonizando los requerimientos de la economía, el empleo, la cohesión social, la igualdad de trato y de oportunidades entre mujeres y hombres, la salud y la seguridad de las personas y la protección del medio ambiente, contribuyendo a la prevención y reducción de la contaminación".

No obstante, matiza la Sala, no puede dejar de ponerse de relieve como, a diferencia de otros principios asociados al desarrollo territorial y urbano sostenible, en el caso del principio de igualdad de trato, la legislación estatal no ha incorporado ningún trámite específico, para su concreción en el planeamiento urbanístico, al contrario de lo acaecido con otros principios.

Siendo esto así, en definitiva, con independencia de los procedimientos específicos de elaboración de los planes de urbanismo en cada una de las Leyes autonómicas, las cuales pueden o no incorporar tramites específicos en materia de género, el principio de igualdad de trato es un principio inspirador de la nueva concepción del desarrollo urbano, que exige una ordenación adecuada y dirigida, entre otros fines, a lograr la igualdad efectiva entre hombres y mujeres, esto es, no es necesario el sometimiento del plan a un trámite específico para que esa perspectiva sea tenida en cuenta y para que, en otro caso, el citado plan pueda ser impugnado y el control judicial alcanzar a dichos extremos. 
En definitiva, se llega a la conclusión, que luego se verá reflejada en la concreta respuesta a la cuestión que presentaba interés casacional objetivo, si bien no es exigible al plan impugnado la incorporación del Informe de impacto de género, tal y como sostiene la Sala de instancia, ello no es óbice para que puedan discutirse a través de la impugnación del Plan, los concretos y específicos aspectos que pueden incidir en una ordenación de naturaleza discriminatoria.

Ahora bien, lo que ocurría en este caso, es que, habiéndose abordado la cuestión desde una perspectiva puramente formal, la cuestión material o de fondo no resultó abordada, esto es, ni la recurrente, ni la sentencia, explican o razonan, qué concretos aspectos del plan pueden resultar contrarios al principio de igualdad de género, por lo que el plan no puede ser objeto de una declaración de nulidad ni en su totalidad, ni en ninguna de sus determinaciones concretas.

En definitiva la sentencia declara como doctrina jurisprudencial que, si bien la cláusula de aplicación supletoria del derecho estatal no permite sostener la exigencia a las Comunidades Autónomas de un requisito, como es el informe de impacto de género, en materia de ordenación urbanística, que no figura previsto en su propia legislación, el principio de igualdad de trato es un principio inspirador de la nueva concepción del desarrollo urbano, que exige una ordenación adecuada y dirigida, entre otros fines, a lograr la igualdad efectiva entre hombres y mujeres, esto es, no es necesario el sometimiento del plan a un trámite específico para que esa perspectiva sea tenida en cuenta y para que, en otro caso, el citado plan pueda ser impugnado y el control judicial alcanzar a dichos extremos.

\section{Bibliografía}

Carballeira Rivera, M.T. (2016): Urbanismo con género. El Derecho de la ciudad y el territorio. (Estudios en homenaje a Manuel Ballbé Prunés). INAP.

Del Oro Pulido, M. \& Suay Rincón, J.J. (Voto particular, Sentencia de 6 de octubre de 2015. Recurso de casación 2676/2012. Tribunal Supremo).

FUeRTES López, M. (Sentencias que anulan planes urbanísticos, 21 de junio 2017).

RAMÓn FERnÁndeZ, T. (2017): "El contencioso urbanístico y su necesaria reforma”. Revista de Administración Pública 203.

Ramos Medrano, J.A. (2017): Actualidad jurídica ambiental, $\mathrm{n}^{\circ}$ 73. (20 de noviembre).

Ruiz Arnalz, G. (2017): "El Informe de impacto de género en el planeamiento territorial y urbanístico". El Derecho, 13 de junio.

Velasco Caballero, F. (2018): "Informe de impacto de género y planeamiento urbanístico: Cuando el TSJ de Madrid crea exigencias procedimentales" (11 de septiembre). 